\title{
Young people's parental discussion about sexual and reproductive health issues and its associated factors in Awabel woreda, Northwest Ethiopia
}

Atitegeb Ayehu', Teketo Kassaw ${ }^{2^{*}}$ and Getachew Hailu²

\begin{abstract}
Background: In Ethiopia besides the very low health seeking behavior of young people, they do not have access to sexual and reproductive health information and even the existing health services are adult-centered. Furthermore, health providers are not well equipped in addressing young people sexual and reproductive health needs. Therefore, parent-young people discussion about sexual and reproductive health issues are crucial in increasing their awareness and reduces their risky sexual behaviors. This study was aimed to assess young people's parental discussion about sexual and reproductive health issues and its associated factors in Awabel woreda, Northwest Ethiopia.
\end{abstract}

Methods: A community based cross-sectional study was conducted among 781 young people aged 10-24 years in Awabel Woreda, Northwest Ethiopia. A pre-tested structured interview administered questionnaire was used for the data collection. The collected data were entered using Epi Data 3.1 and analyzed using SPSS for windows version 21.

Results: In the past 6 months, about one quarter, $25.3 \%$ of young people had a parental discussion about sexual and reproductive health issues. Young people who reside in urban areas were more likely to discuss on sexual and reproductive health issues with their parents [AOR $=2.44,95 \% \mathrm{Cl}: 1.54-3.89]$. Similarly, being male was more likely to have a parental discussion about sexual and reproductive health issues than females $[\mathrm{AOR}=1.63,95 \% \mathrm{Cl}$ : 1.11-2.38]. Furthermore, the odds of parent-young people discussion about SRH matters was more likely among young people aged 20-24 years [AOR $=4.57,95 \% \mathrm{Cl}: 2.13-9.82$ ], living with fathers [AOR $=2.46,95 \% \mathrm{Cl}: 1.20-5.04]$ and had attained a primary level of education [AOR $=2.89,95 \% \mathrm{Cl}: 1.22-6.87]$. Parents lack of interest to discuss, feeling ashamed and culturally not acceptable to talk about sexual matters were found to deter young people's in discussing sexual and reproductive health matters.

Conclusion: Parent-young people discussion about sexual and reproductive health is very low and there are different hindering factors. And therefore, young people's sexual and reproductive health programs or policies should be designed in addressing the cultural and societal factors besides the individual or behavioral factors.

Keywords: Sexual and reproductive health, Adolescent, Youth, Young people, Reproductive health, Parental communication

\footnotetext{
* Correspondence: kteketo@yahoo.com

${ }^{2}$ Department of Public Health, College of Medicine and Health Sciences,

Debre Markos University, PO Box: +251-269, Debre Markos, Ethiopia

Full list of author information is available at the end of the article
} 


\section{Background}

There is overwhelming evidence on the importance of involving parents as part of the comprehensive strategy for improving young people's health and development, however, there has been conflicting study's findings on whether parents in Sub-Saharan Africa discuss with their children about sexual and reproductive health and on the effect of such discussion on young people's sexual behaviour [1]. Though some studies showed that young people who discussed about SRH issues with their parents were less likely to engage in risky sexual behaviours $[2,3]$, but this finding was not consistent with other studies [4, 5]. A systematic review of behavioural studies found that family connectedness, and general and sexuality-specific parent-young people discussion had a protective association with young people sexual and reproductive health outcomes [6].

A qualitative study done in rural Tanzania on parent-child communication on sexual and reproductive health revealed that, though there were some communication; mainly focus on the same sex basis, about sexual and reproductive health issues in most families, the communication was characterized by parental warnings, threats and physical discipline. The topics of discussion were mainly on abstinence, unplanned pregnancy and HIV/AIDS, reflecting the worries that parents had on their children's sexual health. The parent-child communication is limited by cultural barriers and the parents' lack of knowledge about sexual and reproductive health issues [7]. Similarly, in Bangladesh the socio-cultural norms inhibit disclosure of information about sexual activities and other reproductive health issues for unmarried young people [8].

Young people in Ethiopia do not have access to information on sexual and reproductive health issues which have a great impact on their health $[9,10]$. Besides the very low health seeking behavior of young people in Ethiopia, particularly sexual and reproductive health [11], the existing sexual and reproductive health services are adult-centered making them less accessible [12]. Moreover, health service providers are not well equipped in addressing young people's specific health needs [13] and therefore, in this situation, parents, community members and other stakeholders is really crucial in improving the health status of the young people [14].

Even though most young people knew about sexually transmitted infections, particularly HIV/AIDS and contraceptives, they failed to discuss on sexual and reproductive health issues with their parents. More than half of them preferred to discuss about sexual and reproductive health topics with peers and it was due to their lack of communication skill and feeling being ashamed [15]. Due to lack of knowledge, sociocultural norms and parental fear that discussion about reproductive health issues would encourage premarital sex, parent-young people discussion about sexual and reproductive health issues was rare in the Eastern part of Ethiopia, Harar [16].

Parent-young people discussion about sexual and reproductive health issues is believed to be culturally shameful in Ethiopia [17]. Lack of proper knowledge, besides the attached socio-cultural taboos, about sexual and reproductive health matters makes the parent-young people SRH open discussions difficult. This difficulty can be judged from a study done in Zway, Ethiopia, where only $20 \%$ of the parents ever had a discussion on SRH issues with their young people [18].

Though, the two studies conducted in the two regions of the country, Ethiopia showed that $32.5 \%$ of young people in Oromia region [19] and $43.5 \%$ of young people in Tigray region [20] had a parental discussion about sexual and reproductive health issues but the discussions were infrequent and took the form of warning and threatening way [19]. Age, residence, education and living arrangement of young people was significantly associated with parent-young people Sexual and Reproductive Health (SRH) discussion. Young people failed to discuss on sexual and reproductive health issues due to fear of parents, cultural taboos attached to sex, embarrassments, and parents' lack of knowledge of sexual and reproductive health [19]. Furthermore, in Machakle woreda, Northwest Ethiopia three quarters of young people had never discussed on sexual and reproductive health issues with their parents due to its worthlessness, fear, social and cultural taboos attached to it [21].

However, the Ethiopian government had developed a national reproductive health strategy [22] but the role of parent-young people discussion on sexual and reproductive health issues and its current status is not well addressed yet. Parental discussion about sexual and reproductive health issues is very important in improving young people's sexual and reproductive health knowledge, thereby increasing their access and utilization of the services. Therefore, later on, this will bring a reduction of the burden of young people's disease and disabilities associated with sexual and reproductive health. Thus, the purpose of this study was to determine the level of parental discussion about sexual and reproductive health issues and to identify the factors associated with it among young people in Northwest Ethiopia.

\section{Methods}

\section{Study setting and period}

The study was conducted in Awabel Woreda (woreda is Ethiopian common name for district), Northwest Ethiopia from September 1, 2014 to June 30, 2015. The woreda is located at a distance of $259 \mathrm{~km}$ to the Northwest of Addis Ababa, in the Amhara Region. It has a total of 32,253 households and 138,687 populations; 64,506 of 
them are young people [23]. There are 37 health facilities; six health centers, 28 health posts and three private clinics; and a total of 108 health workers and 56 health extension workers in the woreda [24].

\section{Study design and sampling}

It was a community based cross-sectional study conducted among young people in Awabel Woreda, Northwest Ethiopia. The sample size, i.e., 781 was determined using a single population proportion formula taking a proportion (p) of youth friendly reproductive health service utilization in Harar at $63.8 \%$ [25], a $95 \%$ confidence level, $5 \%$ margin of error, a design effect of 2 and $10 \%$ of non-response rate.

The study participants were selected using a multistage sampling technique: at stage one eight kebeles (kebele is the lowest administrative unit in Ethiopia) were selected from the total 29 kebeles; one urban and 28 rural kebeles, in the woreda. One urban kebele (Lumamie Town) was directly taken while seven rural kebeles ( $25 \%$ of the 28 rural kebeles) were taken by using simple random sampling method. In the next stage, using simple random sampling technique, a total of 9216 households having young people were selected in each of the sampled kebeles. Finally 781 young people were selected using the existing Health Post Family Folder through the simple random sampling technique with proportionate allocation to size. Per each household, one eligible young person was interviewed and two visits were made for absences in the first visit.

\section{Data collection}

A structured interview-administered pre-tested Amharic questionnaire was used for the data collection. The purpose of the study was briefly introduced for each of the study participants and data were collected after obtaining a verbal informed consent. The data were collected by trained ten data collectors with health background and two BSc public health supervisors. The data were collected in the quietest corner of young people's house where there was no noise and disturbance. The data collection process had taken an average of 40 minutes.

Data quality was assured through careful questionnaire design, pretest and training. One day training about the purpose of the study, the questionnaire in detail, the data collection procedure, the data collection setting and the rights of study participants in detail was given for the data collectors and supervisors. After each day of data collection, the collected data were checked for completeness and consistency by holding a meeting with the data collectors.

\section{Data analysis}

In this study the term 'parent-young people SRH discussion' refers to parents initiating a discussion on sexual and reproductive health issues, or parental involvement in sexual and reproductive health discussion initiated by the young people, or both. It was measured with a 'Yes' for those who had a parental discussion and 'No' option for those who had no parental discussion as mentioned above.

Data were entered using Epi Data version 3.1 and then exported to SPSS version 21.0 for analysis. Descriptive statistics was used to describe the study population in relation to relevant variables. Bivariate and multivariable logistic regression was done to assess any significant relationship between each independent variable (sociodemographic characteristics) and outcome variable (SRH parental discussion). Crude and adjusted odds ratios were used to ascertain any associations between the dependent and independent variables while significance was determined using a $95 \%$ confidence interval. For not losing the most important variables like mother's education, independent variables with a $p$-value of less than 0.20 at the bivariate level were included in a multivariable logistic regression model. However, any significant association was determined at a $p$-value of less than 0.05 in the multivariable logistic regression model to control potential confounding variables.

\section{Ethical consideration}

Ethical approval was obtained from Debre Markos University, College of Medicine and Health Sciences, Research Ethics Committee and a letter of permission was obtained from the Awabel Woreda Health Office. The purpose of the study was explained to young people and a verbal informed consent was obtained from the participants. For those study participants who were under the age of consent, informed verbal assent was obtained from their parents. Confidentiality of information was maintained by omitting any personal identifier from the questionnaires.

\section{Results \\ Socio-demographic characteristics}

Out of the 781 randomly selected young people, 746 were participated obtaining a response rate of $95.5 \%$. Above half, 389 (52.1\%), of them were females and 545 (73.1\%) were rural residents. The mean age of them was $17.80( \pm 2.65)$ years and the majority of them, 438 $(58.7 \%)$ were in the age group of 15-19 years. Nearly one third, 240 (32.2\%), of young people had attained a preparatory level of education and $568(76.1 \%)$ were students in occupation. Concerning their marital status, $649(87.0 \%)$ were single and most, 471 (63.1\%) of them were living with both parents. Six hundred eleven $(81.9 \%)$ of their mothers and $373(50.3 \%)$ of fathers were illiterate and can read and write in their education respectively (see Table 1 ). 
Table 1 Socio-demographic characteristics of young people in Awabel Woreda, Northwest Ethiopia, 2015

\begin{tabular}{|c|c|c|c|}
\hline \multicolumn{2}{|c|}{ Characteristics of respondents $(n=746)$} & \multirow{2}{*}{$\frac{\text { Numbers }}{357}$} & \multirow{2}{*}{$\frac{\text { Percent }}{47.9}$} \\
\hline Sex & Male & & \\
\hline & Female & 389 & 52.1 \\
\hline \multirow[t]{3}{*}{ Age Group in Years } & $10-14$ & 107 & 14.3 \\
\hline & $15-19$ & 438 & 58.7 \\
\hline & $20-24$ & 201 & 26.9 \\
\hline \multirow[t]{3}{*}{ Religion } & Orthodox & 669 & 89.7 \\
\hline & Muslim & 65 & 8.7 \\
\hline & Protestant & 12 & 1.6 \\
\hline \multirow[t]{2}{*}{ Residence } & Rural & 545 & 73.1 \\
\hline & Urban & 201 & 26.9 \\
\hline \multirow[t]{5}{*}{ Educational Status } & Illiterate & 50 & 6.7 \\
\hline & Read and Write Only & 39 & 5.2 \\
\hline & Primary & 204 & 27.3 \\
\hline & Secondary & 213 & 28.6 \\
\hline & Preparatory & 240 & 32.2 \\
\hline \multirow[t]{2}{*}{ Marital Status } & Single & 649 & 87.0 \\
\hline & Married & 97 & 13.0 \\
\hline \multirow[t]{2}{*}{ Ethnicity } & Amhara & 739 & 99.1 \\
\hline & Oromo & 7 & 0.9 \\
\hline \multirow[t]{4}{*}{ Living Arrangement } & Both parents & 471 & 63.1 \\
\hline & Father only & 112 & 15.0 \\
\hline & Mother only & 66 & 8.8 \\
\hline & With couple & 97 & 13.0 \\
\hline \multirow[t]{4}{*}{ Mother's Education } & Illiterate & 611 & 81.9 \\
\hline & Read \& Write Only & 75 & 10.1 \\
\hline & Primary & 57 & 7.6 \\
\hline & Secondary and Above & 3 & 0.4 \\
\hline \multirow[t]{4}{*}{ Father's Education } & Illiterate & 278 & 37.3 \\
\hline & Read \& Write Only & 375 & 50.3 \\
\hline & Primary & 59 & 7.9 \\
\hline & Secondary and Above & 34 & 4.6 \\
\hline \multirow[t]{3}{*}{ Occupational Status } & Housewife & 74 & 9.9 \\
\hline & Daily Laborer & 100 & 13.4 \\
\hline & Student & 572 & 76.7 \\
\hline
\end{tabular}

Young people's parental discussion about sexual and reproductive health issues

Above half of young people, 386 (51.7 \%) had accepted that it is important to discuss about sexual and reproductive health issues with their parents. However; only $189(25.3 \%)$ of them had a parental discussion on at least one sexual and reproductive health issues in the past 6 months. Out of the 189 young people who had a parental discussion, a very low proportion of them had discussed with their parents about biological aspects of sexual and reproductive health issues such as spermache, 14. (7.4 \%) and menstruation, 24 (12.7\%). Forty seven $(24.9 \%)$ and $40(21.2 \%)$ of young people had reported discussion about the preventive aspects like: abstinence and contraception respectively. Furthermore, 73 (38.6\%) about STI/HIV/AIDS and 34 (18.0\%) of them had discussed about unwanted pregnancy (See Fig. 1).

Individuals involved in the discussion about sexual and reproductive health issues were mothers, 59 (31.4\%); sisters, 54 (28.7\%); fathers, 52 (27.7 \%) and brothers, 23 (12.2\%). Most; 86 (45.5\%) of the discussions were made as it was convenient followed by sometimes, 60 (31.7 \%) (See Fig. 2). On the other hand, 431 $(57.8 \%)$ of them had SRH discussion other than parents, such as with peers, 187 (43.4\%); teachers, 106 (24.6\%); health providers, $99(23.0 \%)$ and peers' parents, 39 $(9.0 \%)$.

The young people's reason for not discussing about sexual and reproductive health issues with parents are shown in Fig. 3. The majority of the reasons were parents' lack of interest to discuss or not a good listener, $184(33.0 \%)$ and fear of parents/shame, 156 (28.0 \%) (See Fig. 3).

\section{Factors associated with young people's parental discussion about SRH issues}

In the bivariate analysis sex, residence, age, living arrangement, educational attainment, and father's education showed significant association on parental discussion about sexual and reproductive health issues. However, in the multivariable analysis father's and mother's education didn't show any significant association with a parental discussion about SRH issues.

The odds of discussing on sexual and reproductive health issues were 1.63 times more likely in males compared to females' [Adjusted Odds Ratio $(\mathrm{AOR})=1.63$, $95 \%$ CI: 1.11 - 2.38]. Young people within the age of 20-24 years were 4.57 times more likely to discuss on $\mathrm{SRH}$ issues with their parents than those within the age of 10-14 years [AOR $=4.57,95 \% \mathrm{CI}: 2.13$ - 9.82].

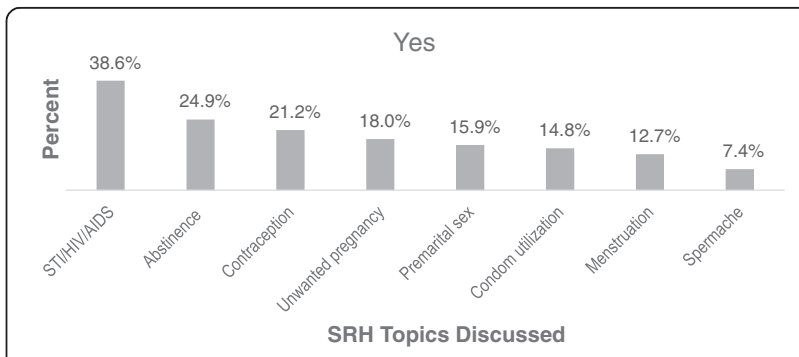

Fig. 1 Sexual and reproductive health topics discussed among young people with their parents in Awabel Woreda, Northwest Ethiopia, $2015(n=189)$ 


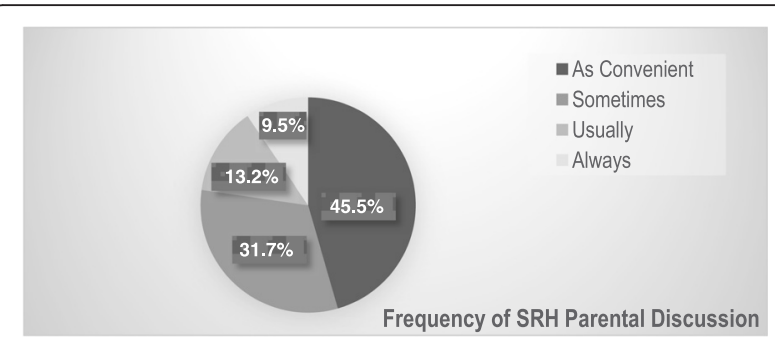

Fig. 2 Frequency of parental discussion on sexual and reproductive health issues among young people in Awabel Woreda, Northwest Ethiopia, $2015(n=189)$

Similarly, the odds of discussing about sexual and reproductive health were 2.46 times higher among young people who were living with their fathers than those living with their couple [AOR $=2.46,95 \%$ CI: 1.20 - 5.04]. Those respondents who had attained primary level of education were 2.89 times more likely to have odds of communication about sexual and reproductive health issues than those who can't read and write $[\mathrm{AOR}=2.89$, 95 \% CI: 1.22 - 6.87]. Furthermore, the odds of SRH parental discussion were 2.44 times more likely among young people who reside in urban areas than those living in rural areas $[\mathrm{AOR}=2.44,95 \% \mathrm{CI}: 1.54$ - 3.89] (See Table 2).

\section{Discussion}

This study revealed that about one quarter of the young people had a parental discussion about sexual and reproductive health issues in Awabel woreda. The discussion was significantly higher, especially among young males and young adult, urban residents, lived with fathers, and had a primary level of educational attainment.

In the past 6 months young people's parental discussion about sexual and reproductive health issues was low $(25.3 \%)$. Though the method of data collection and study participants (parents) differs, the finding was comparable $(26 \%)$ with a study done in the United States of America [26]. This finding was a bit higher than a study conducted in Lesotho (20\%) [27], but, lower than other studies done in Ethiopia, i.e., Debre Markos Town [28]

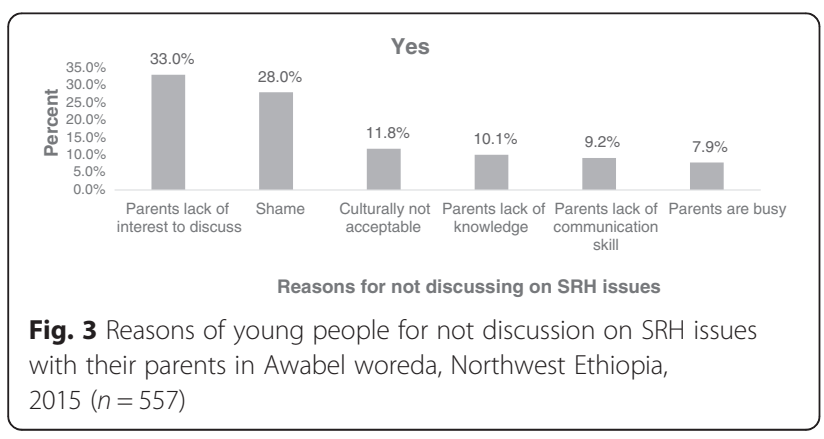

and Bulen Woreda [29] and studies conducted in Ghana (82.3 \%) [30], Zimbabwe (44 \%) [31] and Mexico $(83.1 \%)$ [32]. This difference might be due to differences in the study population, study settings, data collection method and the study design itself as most of the above mentioned studies were conducted among students and urban residents. Furthermore, it might be due to demographic and cultural differences and difference in accessing sexual and reproductive health information.

Parental discussion about sexual and reproductive health issues were significantly associated and higher among young males. This might be due to the fact that males might not be influenced by the social taboos than females. Similarly, systematic review of literatures in Latin America and Caribbean countries found that parent-young people discussion about sexual and reproductive health matters seemed to be more protective for females than males [33]. A qualitative study done in Tanzania revealed that parent-young people discussion about SRH issues was mainly on the same sex basis [7]. This was indicated by other studies done in Bulen Woreda [29] and China [34] as there was a significant gender difference in the pattern of parental discussion about sexual and reproductive health issues. Furthermore, males might have a better educational attainment than females enhancing their knowledge and motored them to discuss about sexual and reproductive health matters.

Young people who reside in urban areas were more likely to discuss on sexual and reproductive health issues than rural residents. This finding was supported by a study done in Eastern Wollega [19]. As studied in Tanzania, young people were hesitated from discussing SRH topics with their parents due to lack of trust and fear of punishment. There in Tanzania, parents were also limited to discuss about SRH issues with their child due to the cultural norms that restricted interactions between opposite sex and lack of appropriate knowledge about SRH matters [7]. However, the aforementioned issues might not be as such a major challenge in urban areas as urban young people might have better knowledge, access to information or media exposure to SRH issues as compared to rural residents and their parents might be educated. This was supported by a study done in Debre Markos town, Ethiopia as young people who had SRH information were more likely to discuss about SRH issues with their parents than those who didn't get SRH information [28].

This study showed that parental discussion about sexual and reproductive health issues was significantly associated and higher with an increase in respondent's age and it was in agreement with other study done in Nekemte, Ethiopia [19] and Nigeria [35]. This could be due to the better understanding of sexual and 
Table 2 Factors associated with young people's parental discussion on sexual and reproductive health issues in Awabel Woreda, Northwest Ethiopia, 2015

\begin{tabular}{|c|c|c|c|c|c|}
\hline \multirow[t]{2}{*}{ Variables $(n=746)$} & & \multicolumn{2}{|c|}{$\underline{\text { SRH parental discussion }}$} & \multirow{2}{*}{$\begin{array}{l}\text { Crude odds ratio } \\
\text { (95\% C.I.) }\end{array}$} & \multirow{2}{*}{$\begin{array}{l}\text { Adjusted odds ratio } \\
\text { (95\% C.I.) }\end{array}$} \\
\hline & & Yes n (\%) & No n (\%) & & \\
\hline \multirow[t]{2}{*}{ Sex } & Female & $123(31.6)$ & $266(68.4)$ & 1.00 & 1.00 \\
\hline & Male & $66(18.5)$ & $291(81.5)$ & $2.04(1.45-2.87)^{* * *}$ & $1.63(1.11-2.38)^{*}$ \\
\hline \multirow[t]{2}{*}{ Residence } & Rural & $157(28.8)$ & $388(71.2)$ & 1.00 & 1.00 \\
\hline & Urban & $32(15.9)$ & $169(84.1)$ & $2.14(1.40-3.26)^{* * *}$ & $2.44(1.54,3.89)^{* * *}$ \\
\hline \multirow[t]{3}{*}{ Age Group in Years } & $10-14$ & 21 (19.6) & $86(80.4)$ & 1.00 & 1.00 \\
\hline & $15-19$ & $148(33.8)$ & $290(66.2)$ & $0.48(0.29-0.80)^{* *}$ & $0.97(0.53-1.77)$ \\
\hline & $20-24$ & $20(10.0)$ & $181(90.0)$ & $2.21(1.14-4.29)^{*}$ & $4.57(2.13-9.82)^{* * *}$ \\
\hline \multirow[t]{4}{*}{ Living Arrangement } & Couple & $31(32.0)$ & $66(68.0)$ & 1.00 & 1.00 \\
\hline & Both Parents & $119(25.3)$ & $352(74.7)$ & $1.39(0.86-2.23)$ & $1.60(0.93-2.76)$ \\
\hline & Father only & $20(17.9)$ & $92(82.1)$ & $2.16(1.13-4.12)^{*}$ & $2.46(1.20-5.04)^{*}$ \\
\hline & Mother only & $19(28.8)$ & $47(71.2)$ & $1.16(0.59-2.30)$ & $1.16(0.53-2.56)$ \\
\hline \multirow[t]{5}{*}{ Educational Status } & Illiterate & $11(22.0)$ & $39(78.0)$ & 1.00 & 1.00 \\
\hline & Read and Write & $7(17.9)$ & $32(82.1)$ & $1.29(0.45-3.71)$ & $1.61(0.53-4.88)$ \\
\hline & Primary & $20(9.8)$ & $184(90.2)$ & $2.60(1.15-5.85)^{*}$ & $2.89(1.22-6.87)^{*}$ \\
\hline & Secondary & $79(37.1)$ & $134(62.9)$ & $0.48(0.23-0.99)^{*}$ & $0.51(0.23-1.13)$ \\
\hline & Preparatory & $72(30.0)$ & $168(70.0)$ & $0.66(0.32-1.36)$ & $0.45(0.20-1.01)$ \\
\hline \multirow[t]{4}{*}{ Mother's Education } & Illiterate & $152(24.9)$ & $459(75.1)$ & 1.00 & 1.00 \\
\hline & Read and write only & $22(29.3)$ & $53(70.7)$ & $0.80(0.47-1.36)$ & $0.73(0.40-1.34)$ \\
\hline & Primary & $13(22.8)$ & $44(77.2)$ & $1.12(0.59-2.14)$ & $0.97(0.48-1.99)$ \\
\hline & Secondary and above & $2(66.7)$ & $1(33.3)$ & $0.17(0.02-1.84)^{+}$ & $0.34(0.03-4.17)$ \\
\hline \multirow[t]{4}{*}{ Father's Education } & Illiterate & $65(23.4)$ & $213(76.6)$ & 1.00 & 1.00 \\
\hline & Read and write only & $96(25.6)$ & $278(74.4)$ & $0.89(0.62-1.27)$ & $1.06(0.71-1.59)$ \\
\hline & Primary & $32(37.3)$ & $37(62.7)$ & $0.51(0.28-0.93)^{*}$ & $0.65(0.34-1.26)$ \\
\hline & Secondary and above & $6(17.6)$ & $28(82.4)$ & $1.42(0.57-3.59)$ & $2.10(0.78-5.68)$ \\
\hline
\end{tabular}

Significant at ${ }^{*} p$-value $<0.05,{ }^{* *} p$-value $<0.01$, and ${ }^{* * *} p$-value $<0.001$, whereas ${ }^{+} p$-value $<0.20$

reproductive health issues influencing them to discuss on it. Earlier studies have also indicated that the extent of communication on sexual and reproductive health matters increases with age and continuing through young adulthood [36].

Living arrangement was significantly associated and higher among young people who were living with their fathers to discuss on SRH matters. Whatever the health services used or the discussions made, living arrangement has influences on sexual and reproductive health issues [37]. This finding was not supported by a study done in Eastern Wollega as young people who were living with other relatives were more likely to discuss on SRH topics [19]. This could be related to their fathers' educational status, and even these young people might be educated and lived in urban areas. Moreover, this could be influenced by gender difference in the pattern of parental discussion about sexual and reproductive health issues as revealed by other studies done in Ethiopia [29] and China [34].
Young people's primary level of educational attainment was significantly associated and higher to discuss on $\mathrm{SRH}$ issues as compared to those who were illiterate. This finding was supported by a study done in Eastern Wollega [19] and Nigeria [35] as their educational attainment increased they were more likely to discuss about sexual and reproductive health issues. However, it was in contrast to a study done in Debre Markos town [28] as young people with a grade level of the $12^{\text {th }}$ were less likely to discuss about SRH topics. In this study young people might overcome the social taboos and their parents might give time to discuss about sexual and reproductive health matters. In addition, age of young people might have influence on sexual and reproductive health discussion, especially for those in the later ages of young people.

Since this study is a community based study done among urban and rural young people and explored the different independent variables, this gives a better and balanced picture of the situation. Moreover, this study 
used the recent information (6 months) to minimize recall bias. However, this study has its own limitation in that the participants' response might have been affected by social desirability which might affect the validity of the result. The fact that the design was cross sectional, may hinder the determination of causality of the relationship. In addition, the in-depth reasons why young people didn't discuss about sexual and reproductive health issue with their parents were not explored through a qualitative study.

This study has a good implication for clinicians in addressing parent-young people communication about sexual and reproductive health issues through providing age appropriate educational health services (sexuality education) for all young people to help them develop communication skills and responsible sexual behaviors. It has also a good implication for policy makers to revitalize the existing national reproductive health strategy. In addition, it gives a good insight for researchers to explore the societal structure in relation to parent-young people sexual and reproductive health discussion. Furthermore, it implies the need for sustainable advocacy works targeting parents and communities on young people's sexual and reproductive health communication.

This study did not address the societal structures how the issues of sexual and reproductive health discussed in the study area. Since it is important to have a comprehensive community based data and the barriers related to parent-young people sexual and reproductive health communication, in the future, ethnographic studies should be conducted to explore the Ethiopian societal structure in relation to parent-young people discussion about sexual and reproductive health issues.

\section{Conclusion}

This study showed that young people's parental discussion about sexual and reproductive health issues was low in Awabel Woreda. Parental discussion was significantly higher among young males and young adults, who lived in urban areas and with their father only and had a primary level of educational attainment. And therefore, young people's sexual and reproductive health programs or policies should be designed in addressing the cultural and societal factors besides the individual or behavioral factors.

\section{Competing interests}

The authors declare that they have no competing interests.

\section{Authors' contributions}

AA wrote the proposal, participated in data collection, and analyzed the data. GH and TK approved the proposal with some revisions, and participated in data analysis. TK wrote the manuscript. We revised drafts of the paper. All authors read and approved the final manuscript.

\section{Acknowledgements}

We would like to appreciate and thank Department of Public Health, Debre Markos University for technical support and Awabel Woreda Health Office. We would like to thank our data collectors and the supervisors for their invaluable effort; without them this study would not have come to be completed. Our deep gratitude also goes to our study participants who volunteered and took their time to give us all the relevant information for the study.

\section{Author details}

'Students Clinic, Debre Markos University, PO Box: +251-269, Debre Markos, Ethiopia. ${ }^{2}$ Department of Public Health, College of Medicine and Health Sciences, Debre Markos University, PO Box: +251-269, Debre Markos, Ethiopia.

Received: 24 July 2015 Accepted: 25 February 2016

Published online: 08 March 2016

\section{References}

1. WHO. Helping parents in developing countries improve Adolescents' health. Geneva: World Health Organisation; 2007.

2. Mireku S. Family communication about HIV/AIDS and sexual behaviour among senior secondary school students in Accra, Ghana. Afr Health Sci. 2003:3:7-14.

3. Ngom P, Magadi MA, Owuor T. Parental presence and adolescent reproductive health among the Nairobi urban poor. J Adolesc Health. 2003;33:369-77.

4. Fuglesang M. Lessons for life-past and present modes of sexuality education in Tanzanian society. Soc Sci Med. 1997;44:1245-54.

5. Babalola S, Tambashe BO, Vondrasek C. Parental factors and sexual risktaking among young people in Cote d'lvoire. Afr J Reprod Health. 2005:9:49-65.

6. Markham CM, Lormand D, Gloppen KM, Peskin MF, Flores B, Low B, et al. Connectedness as a predictor of sexual and reproductive health outcomes for youth. J Adolesc Health. 2010;46:S23-41.

7. Joyce Wamoyi, Angela Fenwick, Mark Urassa, Basia Zaba, Stones W. Parent-child communication about sexual and reproductive health in rural Tanzania: Implications for young people's sexual health interventions. Reproductive Health. 2010:7(6).

8. Barkat A, Majid M. Adolescent Reproductive Health in Bangladesh: Status, Policies, Programs, and Issues. POLICY Project. 2003.

9. Federal Ministry of Health of Ethiopia: Standard on youth friendly reproductive health services: service delivery guidelines and Minimum service delivery package on YFRH services. Addis Ababa: FMOH; 2006:9-26.

10. $\mathrm{FMOH}$ of Ethopia. Assessment of reproductive health needs and youth friendliness in public health facilities in selected urban areas of the Oromia, Amhara, Southern people, and Tigray Regional States. Ethiopia: FMOH, AA; 2006. p. 10

11. Miller BC, Brad B. Family Relationships and Adolescent Pregnancy Risk: A Research Synthesis, Volume 21. Altoona: Academic Press (2001). Developmental Review; 2001:1-38.

12. USAID/Ethiopia. Assessment of Youth Reproductive Health Programs in Ethiopia, 2004. Ethiopia: USAID/Ethiopia; 2004

13. U.S. Agency for International (USAID). The Safe Schools Program Assessment in Ethiopia. 2004.

14. Pav G, Aklilu K, Banteyerga H. Youth Reproductive Health in Ethiopia. Calverton, Maryland: ORC Macro; 2002.

15. Ayalew M, Mengistie B, Semahegn A. Adolescent - parent communication on sexual and reproductive health issues among high school students in Dire Dawa, Eastern Ethiopia: a cross sectional study. Reprod Health. 2014;11:77.

16. Yadeta TA, Bedane HK, Tura AK. Factors affecting parent-adolescent discussion on reproductive health issues in Harar, Eastern Ethiopia: a cross-sectional study. J Environ Public Health. 2014;2014:102579.

17. Taffa N, Bjune G, Sundby J, Gaustad P, Alestrom A. Prevalence of gonococcal and chlamydial infections and sexual risk behavior among youth in Addis Ababa, Ethiopia. Sex Transm Dis. 2002;29(12):828-33.

18. Taffa N, Haimanot R, Desalegn S, Tesfaye A, Mohammed K. Do parents and young people communicate on sexual matters? The situation of family life education (FLE) in rural town of Ethiopia. Ethiop J Health Dev. 1999:15(2):109-16.

19. Tesso DW, Fantahun MA, Enquselassie F. Parent-young people communication about sexual and reproductive health in E/Wollega zone, West Ethiopia: implications for interventions. Reprod Health. 2012;9:13. 
20. Melaku YA, Berhane Y, Kinsman J, Reda HL. Sexual and reproductive health communication and awareness of contraceptive methods among secondary school female students, northern Ethiopia: a cross-sectional study. BMC Public Health. 2014;14:252.

21. Abajobir AA, Seme A. Reproductive health knowledge and services utilization among rural adolescents in east Gojjam zone, Ethiopia: a community-based cross-sectional study. BMC Health Serv Res. 2014;14:138.

22. Federal Democratic Republic of Ethiopia, Ministry of Health. National Reproductive Health Strategy, (2007 - 2015). Addis Ababa: FMOH; 2006.

23. CSA. Population and Housing Census. Addis Ababa, Ethiopia: Ethiopian Central Statistical Agency; 2007.

24. East Gojam Zone Health Department. East Gojam Zone Health Department Annual Health Service Delivery Report 2014

25. Motuma A. Youth-friendly Health Services Utilization and Factors in Harar, Ethiopia. Harar Bulletin of Health Sciences. January 2012 (Extracts Number 4):15-25.

26. Jerman P, Constantine NA. Demographic and psychological predictors of parent-adolescent communication about sex: a representative statewide analysis. J Youth Adolescence. 2010;39:1164-74.

27. Akim J. Parents' attitudes to adolescent sexual behaviour in Lesotho. Population and Poverty Studies Programme 2001.

28. Shiferaw K, Getahun F, Asres G. Assessment of adolescents' communication on sexual and reproductive health matters with parents and associated factors among secondary and preparatory schools' students in Debremarkos town, North West Ethiopia. Reprod Health. 2014;11:2.

29. Gebreysus D, Fantahun M. Assessing communication on sexual and reproductive health issues among high school students with their parents, Bullen Woreda, Benishangul Gumuz Region, North West Ethiopia. Ethiop J Health Dev. 2010;24(2):89-95.

30. Manu AA, Mba CJ, Asare GQ, Odoi-Agyarko K, Asante RKO. Parent-child communication about sexual and reproductive health: evidence from the Brong Ahafo region, Ghana. Reproductive Health. 2015;12:16.

31. Young K, Adrienne K, Ronika N, et al. Promoting sexual responsibility among young people in Zimbabwe. Int Fam Plan Perspect. 2001;27(1):15.

32. Atienzo EE, Walker DM, Campero L, Lamadrid-Figueroa H, Gutie'rrez JP. Parent- adolescent communication about sex in Morelos, Mexico: does it impact sexual behaviours? Eur J of Contrace and Repro Health Care. 2009;14(2):111-9.

33. Markham CM, Lormand D, Gloppen KM, Peskin MF, Flores B, Low B, et al. Connectedness as a predictor of sexual and reproductive health outcomes for youth. J Adolesc Health. 2010;46:23-41.

34. Zhang L, Xiaoming L, lqbal H, Wendey B, Bonita S. Parent-adolescent sex communication in China. Euro J Contracept Reprod Health Care. 2007;12(2):138-47.

35. Berg K, Sun CJ, Babalola S. Predictors of parent-child communication among a nationally representative sample in Nigeria. SAHARA J. 2012;9(2):95-103

36. Byers ES, Sears HA, Weaver AD. Parents' reports of sexual communication with children in kindergarten to Grade 8. J Marriage Fam. 2008;70:86-96.

37. Tegegne TK, Sisay MM. Menstrual hygiene management and school absenteeism among female adolescent students in Northeast Ethiopia. BMC Public Health. 2014;14:1118.

\section{Submit your next manuscript to BioMed Central and we will help you at every step:}

- We accept pre-submission inquiries

- Our selector tool helps you to find the most relevant journal

- We provide round the clock customer support

- Convenient online submission

- Thorough peer review

- Inclusion in PubMed and all major indexing services

- Maximum visibility for your research

Submit your manuscript at www.biomedcentral.com/submit 